\title{
Oxidation Behavior of FeCrAlY Felt at Elevated Temperatures
}

\author{
*Bradley R. Johnson and *Ya-Huei Chin \\ *Pacific Northwest National Laboratory, PO Box 999, K6-24, Richland, WA 99352.
}

FeCrAlY is an iron-based alloy containing additions of chromium, aluminum and yttrium oxide, as well as possible additions of other metals. It is sometimes called an oxide dispersion strengthened (ODS) alloy, and is one of several alloys that are suitable for use at elevated temperatures in oxidizing environments. This alloy has been used in such applications as heating elements, thermal barrier coatings, and in gas turbine engines. Its enhanced oxidation resistance is due to the formation of an adherent native oxide scale on its surface that prevents further oxidation and corrosion of the underlying metal. The protective native oxide scale that forms is composed primarily of aluminum oxide. During the oxidation process, the aluminum at the surface of the alloy reacts with oxygen to form aluminum oxide. This results in a concentration gradient of depleted aluminum at the nearsurface region thereby creating a driving force for the aluminum in the interior of the alloy to diffuse to the surface and also react with oxygen. This is the mechanism by which the adherent native oxide layer forms and grows.

In bulk form, this FeCrAlY withstand service temperatures up to $1300^{\circ} \mathrm{C}$.[1] However, when fabricated as a compressed felt of $10-100 \mu \mathrm{m}$ diameter fibers (Figure 1), rapid oxidation and material degradation has been observed at temperatures as low as $900^{\circ} \mathrm{C}$. The higher surface area to volume ratio in these felts is thought to be the cause for the increased rate of oxidation. Consequently, in order to use FeCrAlY felt at elevated temperatures in oxidizing environments, additional protective coatings are required.

Time, temperature, and oxygen concentration were varied during thermal treatment of FeCrAlY felts to determine their effect on native oxide scale formation and morphology. Microstructures of heattreated FeCrAlY felts were characterized with scanning electron microscopy (SEM) (Figure 2). Oxidation of FeCrAlY felts was studied in-situ using an environmental SEM (ESEM) equipped with a hot-stage. Energy dispersive spectroscopy (EDS) was used to determine chemical compositions.

Oxidation of FeCrAlY felts was observed to be controlled by a nucleation and growth phenomena. The morphology of the native oxide scales varied with the concentration of oxygen during thermal treatment. Native oxide scales formed under oxygen-rich environments were smoother and more continuous than those formed under low oxygen partial pressure conditions (Figure 3). A smoother morphology was considered preferable for subsequent coating processes.

\section{References}

[1] I.G. Wright et al., Proc. $13^{\text {th }}$ Annual Conf. On Fossil Energy Materials, Oak Ridge National Laboratory, 1999

[2] Pacific Northwest National Laboratory is operated by Battelle Memorial Institute for the U.S. Department of Energy under contract DE-AC06-76RL01830 


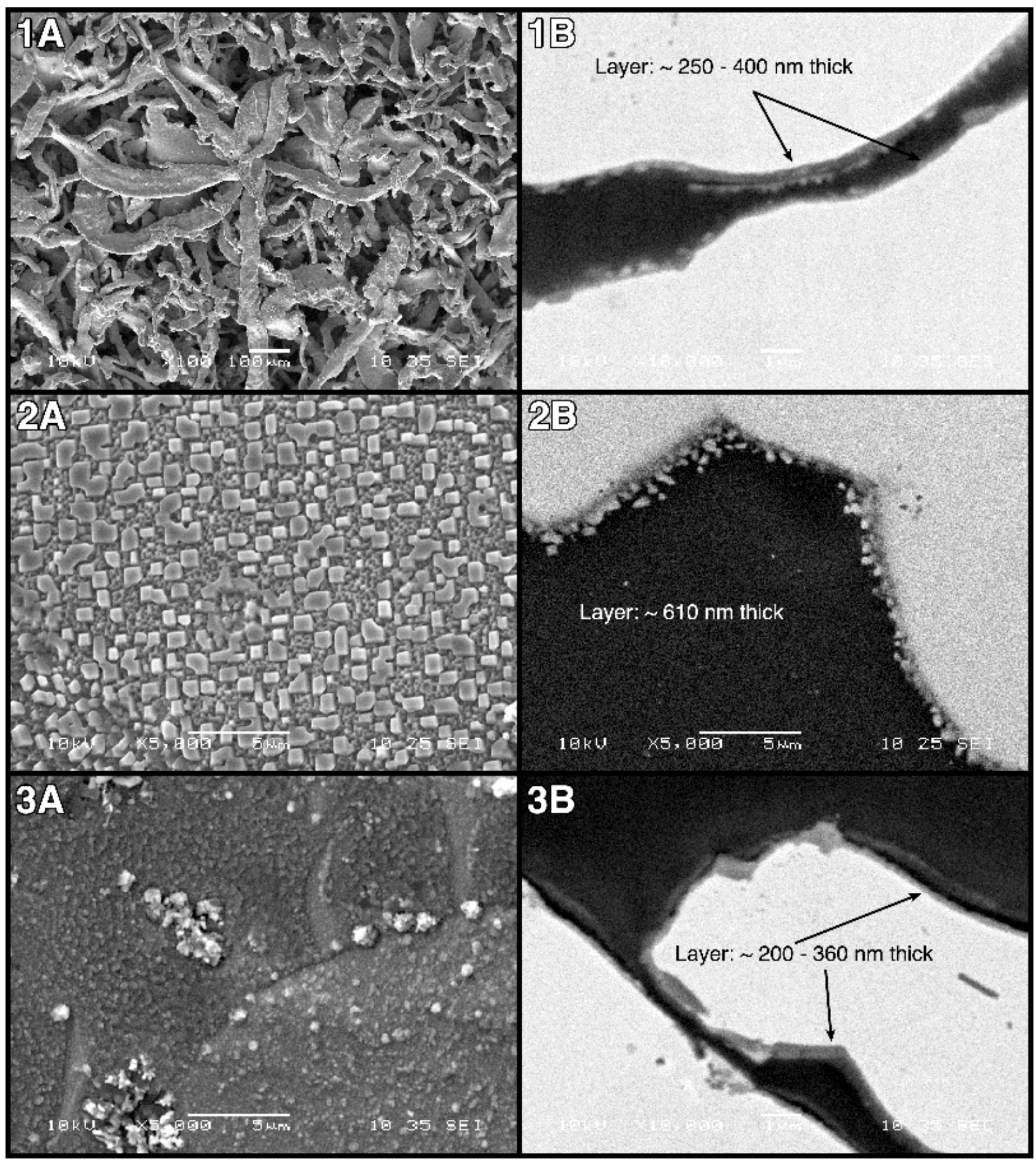

FIG 1-3. Surface and cross-section SEM micrographs of FeCrAlY felt with native oxide layers formed under different conditions.

IA\&B: Heated up to $900^{\circ} \mathrm{C}$ in an $\mathrm{N}_{2}$ atmosphere, and held at that temperature for $2 \mathrm{~h}$.

2A\&B: Heated up to $900^{\circ} \mathrm{C}$ in an $\mathrm{N}_{2}$ atmosphere and held at that temperature for 20 min while air was introduced.

3A\&B: Heated up to $900^{\circ} \mathrm{C}$ in an air atmosphere, and held at that temperature for $2 \mathrm{~h}$. 